\title{
2015 Elijah High Altitude Balloon Launch Team Summer Proceedings Report
}

\author{
Jadee Kellogg, Daniel Ochoa, Jordan Petrie, Alana Tirimacco \\ Milwaukee School of Engineering, attended by Ochoa, Petrie, Tirimacco; Ripon College, \\ attended by Kellogg
}

\begin{abstract}
The 2015 Wisconsin Space Grant Consortium Elijah High Altitude Balloon Launch Team was comprised of three students from Milwaukee School of Engineering and one student from Ripon College. This year, all members of the team had experience with high altitude balloon launches due to previous participation on either the Elijah Payload or Launch Team, or both. A training session was hosted by the 2014 Elijah Launch Team to familiarize the new team with the physical set up of a launch train as well as how to run track predictions and how to read the jet stream charts. Launches were planned for both Carthage College and the Elijah High Altitude Balloon Payload Team, but only the launch for the Payload Team came to fruition. This launch was successful, reaching a peak altitude of $31,021 \mathrm{~m}$.
\end{abstract}

\section{Introduction}

The purpose of the 2015 Wisconsin Space Grant Consortium (WSGC) Elijah Balloon Launch program was to provide four students from WSGC affiliate universities with the opportunity to organize and launch high altitude weather balloons in order to fly science experiments in nearspace environments. The team was responsible for coordinating with the WSGC Elijah Balloon Payload design team in order to create and execute a flight plan in order to carry the payload constructed by the design team to an altitude of approximately $31,000 \mathrm{~m}$ in elevation.

The balloon launch program provided the team members with experience in planning and organizing experiments and scientific events. The team needed to coordinate with multiple third parties which provided the opportunity to improve on their communication and problem solving techniques.

\section{Launch Planning}

Team meetings. The team held meetings throughout the summer to discuss and plan the launch of the scientific payload built by the Elijah High Altitude Payload Team. Due to the geographical locations of the members, these meetings occurred online using Skype. On 22 July 2015, the Launch and Payload teams met to discuss the prospective launch for the Payload team, scheduling it for 5 August 2015. The launch team continued to run predictions and check weather at their various locations leading up to the scheduled launch. On 4 August 2015, the day before the launch, Launch Team member Jordan Petrie met with the Payload Team to train them on how to use the launch equipment.

Flight predictions. A key part of choosing a launch location was the predicted flight path. In preparation for a launch, the team conducted daily flight predictions using an online software created by Cambridge University Spaceflight to find an appropriate launch location (Greig, March 2010). The team began running these predictions beginning seven days before launch up until the morning of the launch itself. Both the launch and landing locations were required to be over five miles away from any airports and free of trees, power lines, and wind turbines. The landing location also needed to be at least five miles away from a large body of water, such as Lake 
Michigan. Over the years, a list of launch locations had been complied by the launch teams (Farrow, et. al., 8 July 2014). The location was chosen from this list, as long as it met all of the requirements laid out for a launch location. Based on the predicted flight paths, Mount Horeb, WI was chosen as the launch location for the Payload Team's flight. Figure 1 is a screen capture of the final path prediction run before the launch for the Payload Team occurred.

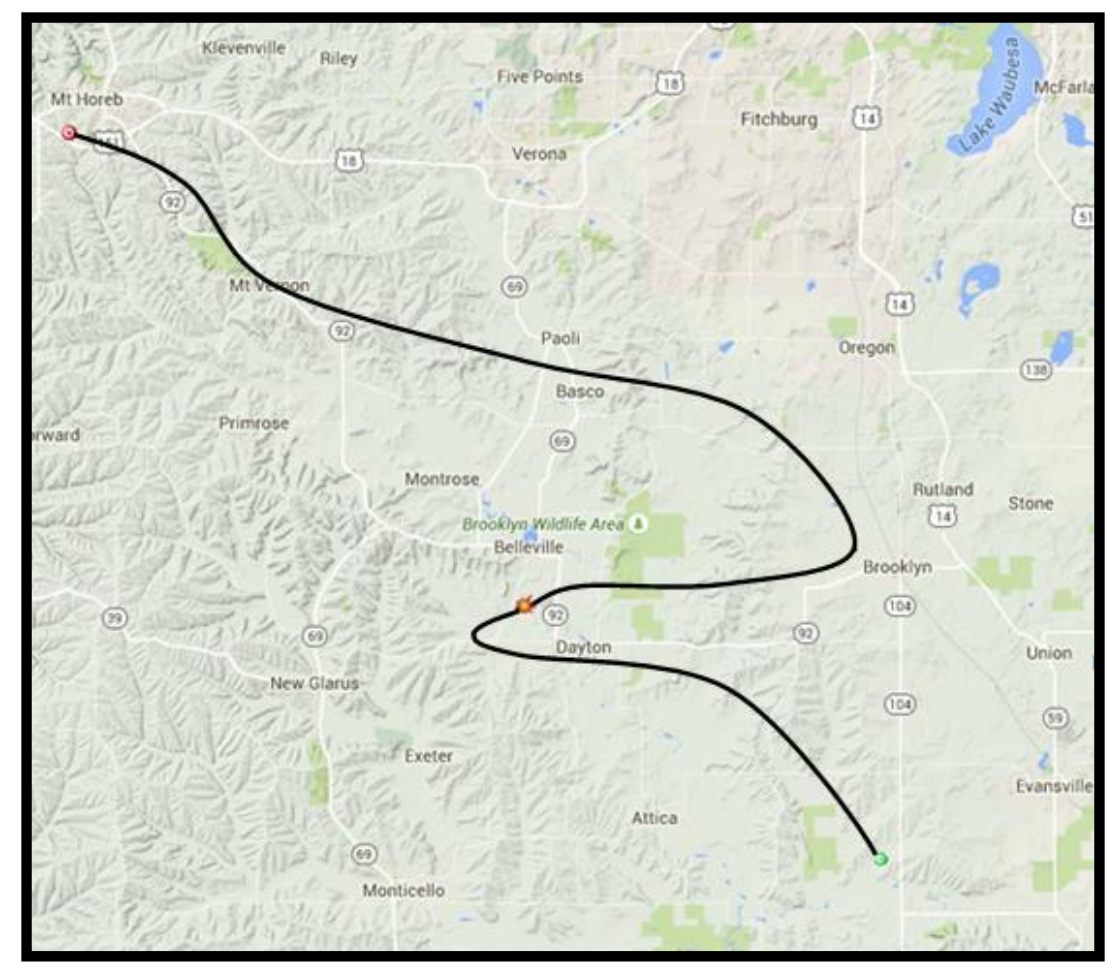

Figure 1: The last path prediction run before the launch for the Payload Team on 5 August 2015 in Mount Horeb, WI.

Weather forecasting. The weather forecast and jet stream were also analyzed beginning five days before launch. The team looked at wind speeds and ground weather using weather reports and analyzed the jet stream using an online program created by affiliates of San Francisco State University (Dempsey, 19 June 2012). Figure 2 shows the jet stream map for the 5 August 2015 launch. The speed of the jet stream on launch day was less than $60 \mathrm{mph}$, which meant the team was able to launch the balloon without fear of the jet stream winds interfering with the flight. 


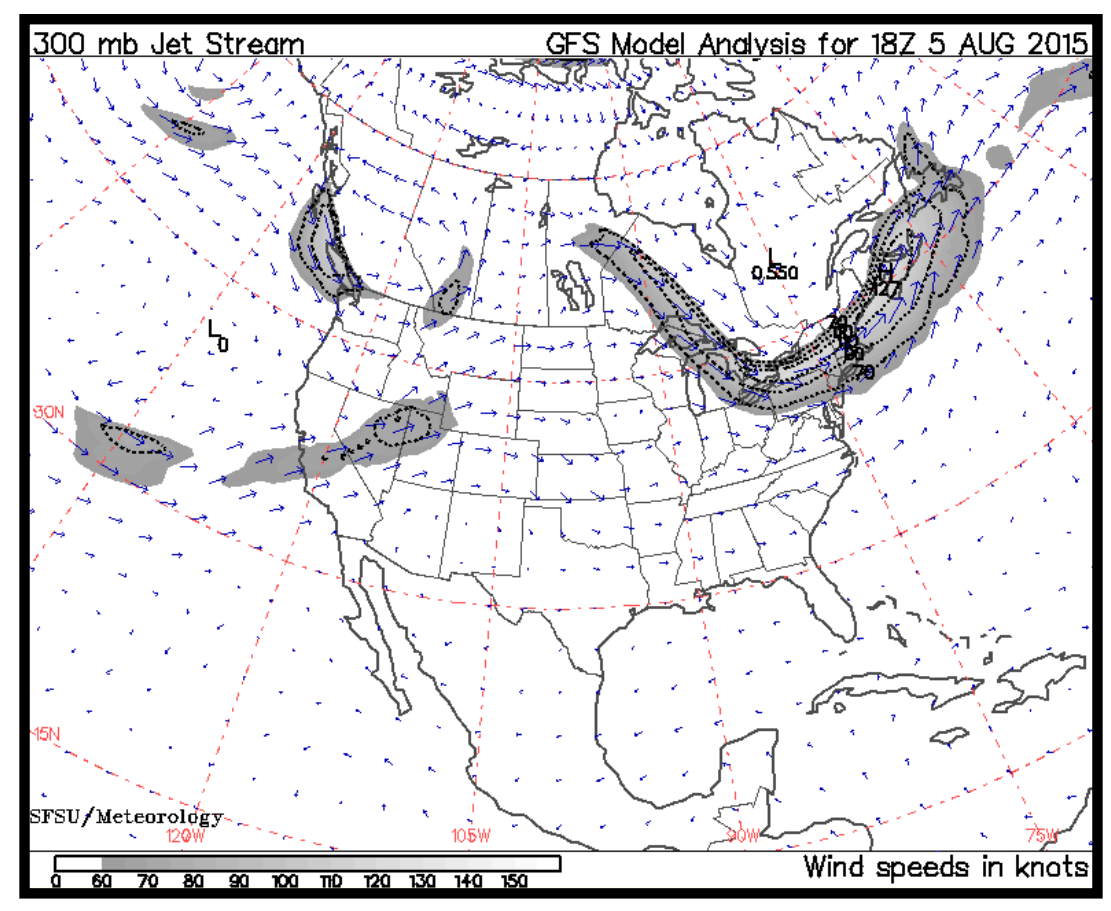

Figure 2: Jet Steam for 5 August 2015 - Launch Successful

Balloon and payload set-up. The balloon was set up with the goal to successfully recover the payload in an undamaged condition. To increase the chances of this, the balloon had two tracking payloads attached to it. The primary tracking payload used GPS to transmit its location to Microsoft Mappoint, a tracking software downloaded on the laptops in the Chase Vehicles. The secondary payload sent out a radio signal that could be tracked inputting the frequency of the tracker to a website, enabling the team to collect the data. The purpose of having two tracking payloads was to have a fail-safe in case one of them stopped working. Both tracking payloads were battery powered and were insulated to avoid damage from the low temperatures of the upper atmosphere. The balloon also had a parachute attached that opened when the balloon burst at its apogee. The purpose of the parachute was to slow the descent of the payloads in order to prevent damage to them upon landing. The scientific payload launched was designed by the Elijah High Altitude Payload Team. The payload contained experiments researching oxygen generation, internal heating, ozone detection, and the speed of sound.

The balloon set up from top to bottom goes as follows:

1. Balloon

2. Parachute

3. Primary Tracking Payload

4. Secondary Tracking Payload

5. Elijah Payload Team Scientific Experimental Payload 


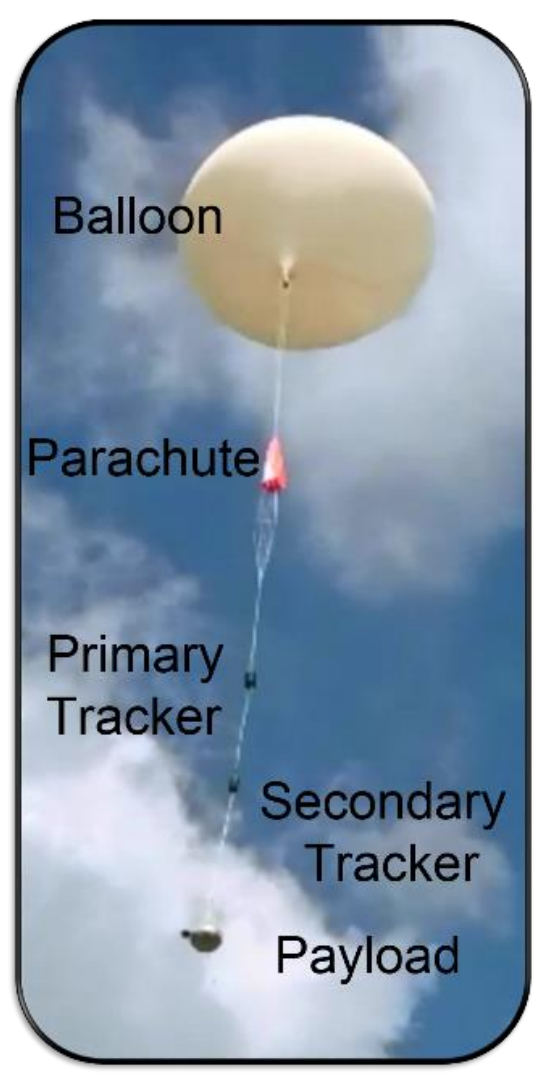

Figure 2: Image of Balloon Set-Up

\section{Launch}

The launch team successfully completed one launch that took place on August $5^{\text {th }}$. This launch was for the payload team where they were able to test their payload. Figure 5 shows the actual path the balloon took during flight. It was extremely similar to the predicted track, shown in Figure 1, supporting the reliability of the prediction software. 


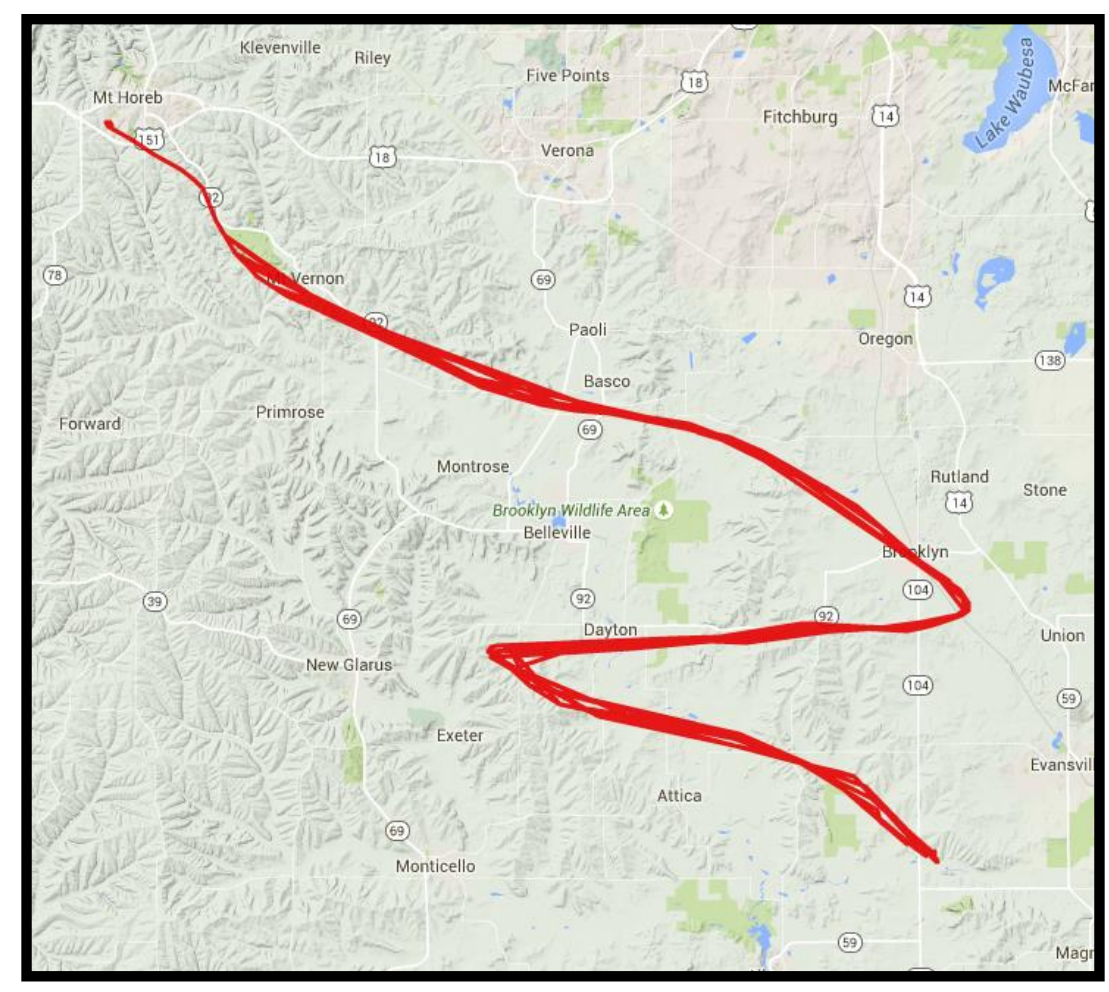

Figure 3: Actual Balloon Track

The launch took place in Mt. Horeb, WI, which had a latitude and longitude of $43.00^{\circ}$ and $-89.75^{\circ}$ respectively. The elevation of the launch location was 1160 meters and the jet stream speed for that day was under $69 \mathrm{mph}$.

Overall for this launch, and the launch team, there were many successes. For example, the team was able to select a satisfactory launch location from a list of possibilities all throughout Wisconsin. The payload was successfully launched, despite troublesome ground wind, reached peak altitude of 31,021 meters before bursting, and safely recovered from a tree. Finally, the team met weekly via Skype to encourage positive communication even when regular face-to-face meetings were impractical.

Cancelled launches. This past spring, Dr. Matthew Zorn from Carthage College contacted the 2014-2015 Launch team, expressing interest in conducting a launch with the group. Dr. Zorn wished to bring his classes, specifically meteorology courses, to launches so that they could analyze the balloon's flight and subsequent data. For the launch to be as beneficial as possible for all involved parties, last year's Launch Team decided to use the Launch as a training experience for this year's team. The launch date was set for 18 April 2015 with 19 April 2015 as the "rain date." A small training session was held on the ground on 8 April 2015. Unfortunately, jet stream and ground wind conditions led to both 18,19 April 2015 launches being cancelled. The launch was then rescheduled for 26 April 2015, but once again, it was cancelled due to wind and weather conditions. With the end of the school year approaching, Dr. Zorn's students were unable to attend another launch. Since the new launch team had already had a ground training session, the teams felt it unnecessary to launch a balloon only for the new team since helium is in short supply and 
launches are expensive. The team plans to be in contact with Dr. Zorn again during the 2015-2016 academic year to attempt to fly a meteorological payload for his classes.

\section{Conclusion}

Overall the team had great communication throughout the summer and was well prepared for the launch on 5 August 2015. The team was able to develop teamwork, problem solving, and organizational skills while learning how to plan and conduct high altitude balloon launches. The team hopes to complete at least one more successful launch in fall 2015 for Carthage College and then another launch in spring 2015 to train next year's Launch Team. 


\section{References}

Dempsey, Dave, PhD. "Animation of Jet Stream Forecasts for North America." Jet Stream Analyses and Forecasts at 300mb. Department of Earth \& Climate Sciences, 19 June 2012. Web. July-Aug. 2015.

Farrow, William, PhD, Alana D. Tirimacco, and Amber L. Korn. Potential Launch Locations. N.p.: Google Drive, 8 July 2014. DOCX. <https://drive.google.com/file/d/0ByGu7nL B3XJKa0d5SGtuTXhHUXc/view?usp=sharing $>$.

Greig, Adam. "CUSF Landing Predictor 2.5." Cambridge University Space Flight. Cambridge University, Mar. 2010. Web. July-Aug. 2015. 